\title{
Interactive comment on "Climate warming has led to the degradation of permafrost stability in the past half century over the Qinghai-Tibet Plateau" by Youhua Ran et al.
}

Youhua Ran et al.

ranyh@Izb.ac.cn

Received and published: 9 November 2017

Responses to Anonymous Referee \#2's Comments and Suggestions (The answers are shown in blue)

Interactive comment on "Climate warming has led to the degradation of permafrost stability in the past half century over the Qinghai-Tibet Plateau" by Youhua Ran et al. Anonymous Referee \#2 Received and published: 26 September 2017

General Comments: The submitted potential publication by Ran et al. to The Cryophere titled "Climate warming has led to the degradation of permafrost stability in the 
past half century over the Qinghai-Tibet Plateau" examines modelled Mean Annual Air Temperature (MAAT) over a period of several decades to assess changes to permafrost stability as categorized by an existing classification scheme by Cheng (1984). Overall the feel that considerable effort, research and writing has gone into the preparation of this manuscript. The authors use a combination of climate data recorded at 152 sites and remote sensed data with six independent variables to spatially infill using a Geographically Weighted Regression (GWR) model. This paper is promising and I believe can be suitable for publication in TC following some moderate revisions and additional analysis. Although the paper is generally well written I find certain sections to be not needed while a much clearer and better stated methods section is needed. Additionally, the Results and Discussion sections should be separated and more distinct. I am somewhat critical of some of the assumptions the authors have made in the methodology of this research and also feel the rational has been poorly explained. The authors must also more clearly understand the potential problems of only using MAAT as a predictor of permafrost. Although I am not opposed to using MAAT in any way, more discussion of specific problems and errors this can cause should be examined. I am happy to review this paper again in the future and will work with the editor and authors regarding this manuscript. I have several specific comments about various elements of the paper which I will go into specific detail below. Thank you very much. We completely agree with your comments. According to your very insight and helpful comments, many revisions have been made. First, we have revised the method section to improve it by adding an overall description of the method. Second, the results and discussion sections should be separated and more distinct. The uncertainty of the MAAT model is explicitly discussed in the discussion section and mentioned in the method section. We also clarified the assumptions for the simulation of MAAT in the past five decades. Lastly, specific comments were modified. We have included the revised version of the manuscript and a document showing the specific changes made in the manuscript.

Printer-friendly version

Discussion paper

Global edits in the paper: 1) The use of the word altitude is improper throughout the

Interactive

comment 
paper. Altitude implies flying height above in earth's surface. I can see nowhere in the paper where this term should be used and the word elevation which refers to height above sea level should be used. The distinction becomes very important in the age of UAVs and MUST be changed in the paper and figures. Thank you very much. This has been modified, and elevation is used throughout the manuscript.

2) A space should be left between all numbers and units in the paper and figures. Example for temperature $0 \_C$ should be used and not $0 \_C$. Thank you very much. We modified this in the revised manuscript.

Specific Comments: 1) Abstract: here the authors use the correct term of "elevation" and generally the abstract describes the paper and research well. Many thanks for your encouragement. We have unified the term, and the word "elevation" is used throughout the manuscript.

2) Introduction: I feel the introduction is very long. I would recommend finding a way to shorten this section by about $15 \%$. Additionally, I think the authors should also add subsections to the introduction including one for background and one for the goals of the paper. I found while reviewing the paper and reading the introduction it was very difficult to tell if the authors were describing their research or past contributions by other authors. Thank you. We have shortened and clarified this section in the revised manuscript.

3) Page 1 - line 29, change "soil or rock" to "earth materials". Thank you. This has been modified in the revised manuscript.

4) Page 2 - line 10, I noticed the term "significant" is used to describe permafrost degradation. Has statistical significance been measured in this occurrence? If not this should be changed to "substantial". Thank you. This has been modified in the revised manuscript. The term "substantial" is used.

Printer-friendly version

5) Page 2 - line 19, here the term "permafrost table" should be replace with "active 
layer" from what I read. Either way I find this statement hard to read and should be changed. Thank you. The term "active layer" is used in the revised manuscript.

6) Page 2 - line 26, The term "relationship" is used and should be changed to "relation". Thank you. This has been modified in the revised manuscript.

7) Page 2 - line 34, here the reference of Cheng and Jin (2013) is used however, I think more references are needed here. Thank you. More references have been added in the revised manuscript.

8) Introduction: the last four lines of the introduction (page 3 - lines 1-4) are not needed and should be removed. Thank you. We have removed the four lines.

9) I find the methods section hard to follow. The first part of the methods section actually presents some background which is useful but perhaps this should be in the introduction. Thank you very much. We have moved this part of the description into the introduction section.

10) More justification as to how the classification for permafrost stability from MAAT needs to be introduced as well as a better justification (e.g. -1_C for extremely unstable permafrost, Why?) Thank you very much. The permafrost stability system was proposed based on the MAGT measurement as an index by analyzing the threedimensional zonation of the high-elevation permafrost (vertical, latitudinal, and aridity). It is a high-level summary of high altitude permafrost zonation. The MAAT index was given according to the statistical relation between MAGT, elevation, and the in situ MAAT measurement (Cheng, 1984). The extremely unstable type in the thermal stability classification system refers to regions that include cave ice and frozen gravel below the lower limit of permafrost, which is a very scattered distribution. In this paper, a MAAT of -1 âĎČ is simply used to distinguish extremely unstable permafrost from seasonally frozen ground.

11) Where other variables tried when the model was created (e.g. Solar radiation?). 
Thank you. The land surface temperature (LST), vegetation, snow cover, elevation, latitude, and longitude were used as independent variables to create the model. LST is a result of energy balance; it largely reflects the space distribution of solar radiation. Additionally, high resolution solar radiation data are currently unavailable.

12) I found it very difficult to relate the modeled results of the GWR with the air temperatures from previous decades. The authors make some big assumptions regarding the patterns of vegetation, snow cover and other metrics being consistent over the past 50 years. The feel the authors need to support the assumption much better with references and additional text. Additionally, although I understand why MAAT was calculated for the different decades the authors need to do a much better job explaining how this is done any how the land surface variables from 2006-10 play into calculations of MAAT from the past. I had to read this section several times and feel the explanation can be simplified. Additionally, I feel the authors should conduct some additional analysis where the parameters used in the GWR are varied to test the spatial impact and robustness in the model which can be done to further support the assumptions used in the model over the 50-year period. Thank you very much. We have improved the description in section 2.2. The analysis shows that the use of the MAST, the leaf area index (LAI), the fractional snow cover (FSC), elevation, latitude, and longitude as independent variables results in the highest degree of explanatory power for the past five decades, and the significance level is less than 0.0001 . Then, the five GWR models corresponding to the five decades are used to estimate the decadal mean MAAT over the QTP for the past five decades. We also added one paragraph to the potential error derived from the assumptions regarding the patterns of vegetation, snow cover and other metrics being consistent over the past 50 years. Recent studies show that vegetation is increasing overall during the past 30 years, and the snow cover is decreasing overall during the past 15 years over the QTP (Wang et al., 2016; Huang et al., 2017). The effect of vegetation and snow cover change on MAAT is very complex. For example, the vegetation-snow interaction affects MAAT and is related to humidity (Wang et al., 2013; Wu et al., 2015; Yuan et al., 2017). However, we believe this error mainly

Printer-friendly version

Discussion paper 
occurs at the local level in vegetation-dominated areas where the change occurred at the local level within the last 50 years, and it can be partially compensated by in situ MAAT measurement over QTP for the past 50 years.

13) Page 5, line 19: what program is the GWR conducted in? Please include. Thank you. We have added additional details to implement the program. Specifically, the GWR for the multiple predictor grids geoprocessing tool is used. The Gaussian weighting function and the global search range are used.

14) Page 7, line 13: here it mentions the 152 climate stations from 1960-2010, what is the sapling rate of data collection? Did data gaps exist? If so how were the gaps filled? Thank you. The in situ MAAT data acquired from the data centre of the China Meteorological Administration did not contain gaps.

15) The results and discussion sections should be clearly separated. Thank you. We separated the results and discussion sections. The discussion section was also improved for uncertainty analysis.

16) Page 8, line 18-20: here the reference by Pepin et al. (2015) in Nature Climate change should be included. Yes, this is a very important reference for the elevationdependent warming. It has been included in the revised manuscript.

17) Page 10, line 3: the authors say that ground temperature is independent of MAAT. I feel independent is too strong a word. The two are not the same but they are not truly independent. Thank you. This is an inappropriate word. We have modified this in the revised manuscript. We added a sentence for clarification. The complex process of and limited knowledge on the permafrost-glacier interaction may enhance the uncertainty.

18) Table 1: are there areas where MAAT is above $0 \_$C? How are they classified here this should be included. Thank you. The $0.5^{\circ} \mathrm{C}$ MAGT isotherm, NOT MAAT, was used to distinguish permafrost from seasonally frozen soil because permafrost exists in areas where the MAGT is greater than 0 âĎČ on the QTP (Cheng, 1984; Luo et al.,

Printer-friendly version

Discussion paper 
$2012 ; 2013)$. This permafrost is generally relatively thin and is found at either deep or shallow depths.

19) Table 5: why is the R2 so low for extremely stable permafrost compared to the others? This should be discussed more. Thank you. The low R2 was mainly affected by the fluctuating mean elevation of extremely stable permafrost during the 1970 s to 1980s. We have discussed this in section 3.2.3. For the extremely stable type, the mean elevation of the distribution decreased from $5240 \mathrm{~m}$ to $5161 \mathrm{~m}$ from the $1960 \mathrm{~s}$ to the 1970 s and then rose continuously at a rate of approximately $56.4 \mathrm{~m}$ per decade. The reduction in elevation is mainly due to the degradation of the extremely stable permafrost type in the Kailas Mountains. This caused the fluctuation of mean elevation for extremely stable permafrost during the 1970s to 1980s and reduced its statistical significance (low $R$ in Table 5) for the rate of increase of mean elevation over the past 50 years. As a whole, over the past 50 years, the mean rate of increase of the extremely stable type has been approximately $24.7 \mathrm{~m}$ per decade.

20) Figure 5: I find this figure hard to read and feel it could be omitted. Thank you. Yes, the figure is redundant. We have removed it.

21) Figure 6: the figure caption should be more clearly written. Thank you. We have modified this caption.

Please also note the supplement to this comment:

https://www.the-cryosphere-discuss.net/tc-2017-120/tc-2017-120-AC2-

supplement.pdf

Interactive comment on The Cryosphere Discuss., https://doi.org/10.5194/tc-2017-120, 2017. 